\title{
MYRCIARIAMYIA BIVALVA, GEN.N. E SP.N. (DIPTERA, CECIDOMYIIDAE, OLIGOTROPHINI) ASSOCIADO COM MYRCIARIA FLORIBUNDA (CAMB.) LEGR. (MYRTACEAE) NO BRASIL
}

\author{
Valéria Cid Maia ${ }^{1}$
}

\begin{abstract}
MYRCLARLAMYLA BIVALVA, GEN.N. AND SP.N. (DIPTERA, CECIDOMYIIDAE, OligotrophinI) ASSOCIATED WITH MYrciaria FloribUNda (CAMB.) LEgR. (MYRTACEAE) IN BRAZIL. Myrciariamyia bivalva, gen.n., sp.n. associated with Myrciaria floribunda (Myrtaceae), in Brazil, is described and illustrated (larva, pupa, male, female and gall).

KEY WORDS. Diptera, Cecidomyiidae, Myrciaria floribunda, Myrtaceae, taxonomy
\end{abstract}

A Restinga de Barra de Maricá (Maricá, Rio de Janeiro) é um ambiente rico em galhas de Cecidomyiidae (Diptera), principalmente em Myrtaceae, familia bem representada nesse ambiente (SILVA \& SONNER 1984).

Nessa Restinga foram coletadas sistemeticamente, no período de março-1992 a março-1994, galhas de gemas axilares e apicais em Myrciaria floribunda (Camb.) Legr. (Myrtaceae). As galhas foram trazidas para o laboratório em sacos plásticos devidamente etiquetados. Algumas delas foram dissecadas sob microscópio estereoscópico, para averiguação da espécie inclutora, retirada da larva e/ou pupa galhadora e observação de características gerais internas da galha. As demais foram acondicionadas em recipientes de vidro, para obtenção de adultos.

Amostras das galhas foram conservadas em vidros com álcool a $70 \%$. As larvas, pupas e adultos foram preparados e montados em lâmina, segundo metodologia de GAGNÉ (1989).

Todos os exemplares estudados encontram-se depositados na Coleção de Diptera do Museu Nacional do Rio de Janeiro (MNRJ).

\section{Myrciariamyia, gen.n. \\ Figs $1,4-6,8-11,13$}

Diagnose. Antenas com 23 flagelômeros no macho e 29 na fêmea; palpos com quatro artículos; garras tarsais, aproximadamente tão longas quanto o empódio, ovipositor pouco protátil e cercos femininos separados. Larva com espátula protorácica reduzida e todas as papilas setosas.

Adulto. Cabeça (Fig. 1): olhos não contínuos no vértice; antena com

1) Museu Nacional do Rio de Janeiro, Quinta da Boa Vista, 20940-040 Rio de Janeiro, Rio de Janeiro, Brasil. Bolsista da CAPES. 

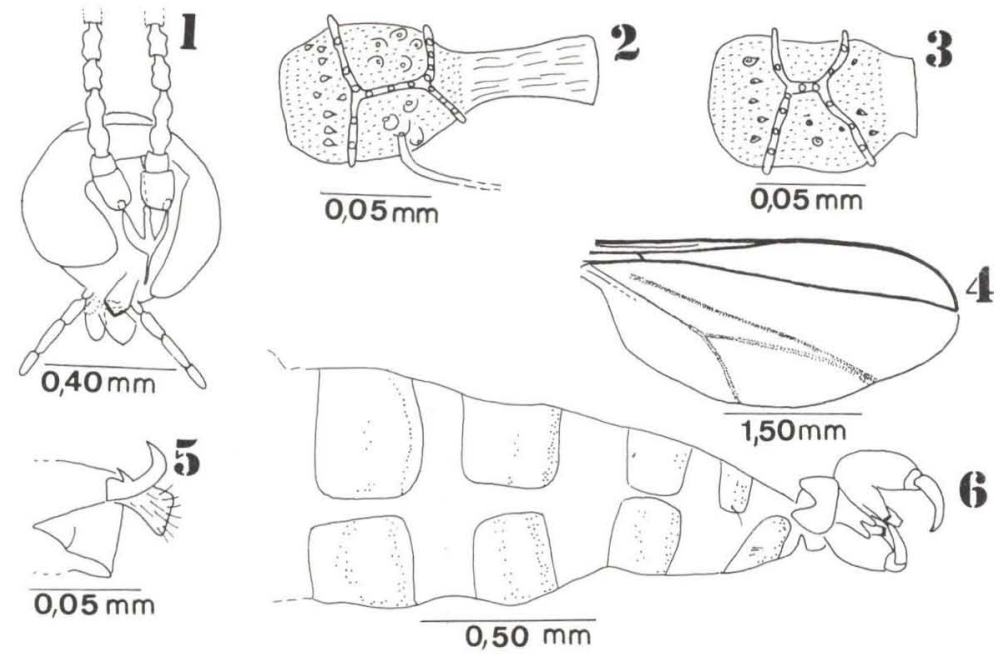

Figs 1-6. Myrciariamyia bivalva, sp.n. (1) Macho, cabeça. vista frontal; (2) macho, flagelômero V; (3) fềmea, flagelômero IV; (4) macho, asa; (5) macho, garra tarsal; (6) macho, segmentos abdominais V-VIII e genitália.

número de flagelômeros variável (23 no macho e 29 na fêmea); palpo com quatro artículos alongados e setosos; labela hemisférica; labro triangular, cobrindo parcialmente a hipofaringe. Asa (Fig. 4) com R5 encontrando $\mathrm{C}$ no ápice alar; $\mathrm{M}_{3}$ evanescente; $\mathrm{Cu}$ bifurcada e ambos os ramos alcançando a margem da asa. Pernas longas, finas, semelhantes entre si; garras tarsais (Fig. 5) com um dente longo, aproximadamente tão longas quanto o empódio e curvas após a metade de seu comprimento. Abdômen do macho: tergitos I-VIII e esternitos I-VIII retangulares, uniformemente esclerotinizados e com cerdas distribuídas como na figura 6; terminália: cerco bilobado, hipoprocto bilobado; edeago mais longo que o hipoprocto; gonocoxito amplo; gonóstilo longo, afilando para o ápice. Abdômen da fêmea: ovipositor pouco protrátil; tergitos I-VI retangulares, uniformemente esclerotinizados, com cerdas distribuídas como no tergito VI da figura 8 , tergito VII retangular com cerdas dispostas como na figura 8 , tergito VIII ovalado com cerdas distribuídas como na figura. 8; esternitos I-V retangulares, com cerdas distribuídas como na figura 9, esternito VI e VII retangulares com cerdas distribuídas como na figura 8; cercos grandes, não fundidos, e um pequeno hipoprocto ventral (Fig. 10).

Pupa: chifres antenais pouco desenvolvidos; região cefálica com um espessamento na margem superior, próximo à cobertura de cada antena (Fig. 11); segmentos abdominais II-VIII com espinhos dorsais.

Larva: espátula com dois dentes anteriores desenvolvidos e haste reduzida (Fig. 13).

Myrciariamyia foi incluído na tribo Oligotrophini, com base em caracteres da antena, garras tarsais, empódio e genitália masculina. Entre os gêneros neotropicais já conhecidos, este novo gênero se aproxima mais de Promikiola 
Kieffer \& Herbst, 1911 (conhecido apenas pela fêmea e pupa) por apresentar palpo com quatro artículos, garras tarsais denteadas e cercos femininos separados; no entanto, difere deste pela presença da veia $\mathrm{M}_{3}$ (ausente em Promikiola, Fig. 5 de KiefFER \& HeRBSt 1911) e pela pupa com cifres antenais pequenos (em Promikiola bem desenvolvidos e de duas a três vezes ma is longoos que largosos).

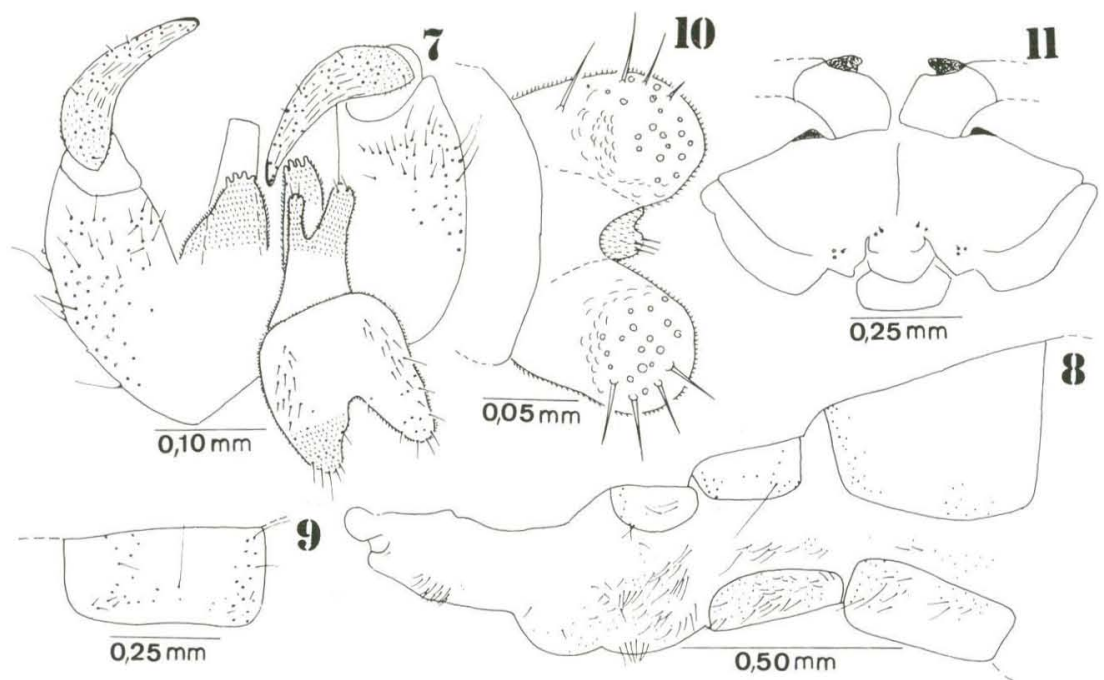

Figs 7-11. Myrciariamyia bivalva, sp.n. (7) Macho, genitália, vista dorsal; (8) fêmea, segmentos abdominais VI-VIII e ovipositor, vista lateral; (9) fềmea, esternito V: (10) fêmea, cercos, vista dorsal; (11) pupa, região cefálica, vista ventral.

\section{Myrciariamyia bivalva, sp.n.}

Figs $2-5,7-8,10-17$

Macho adulto. Comprimento: 3,3-5,0mm; asa: 3,0-5,0mm. Cabeça: olhos com facetas hexagonais intimamente aproximadas entre si nos $2 / 3$ inferiores da região cefálica e irregularmente afastadas entre si no terço superior. Antenas com escapo bem desenvolvido, medindo 1,11-1,44 vezes o seu próprio diâmetro e $1,42-1,85$ vezes o comprimento do pedicelo, primeiro e segundo flagelômeros, com 23 flagelômeros separados por um pescoço longo e ornados como na figura 2 ; cerda mais longa do flagelômero cerca de 2,5 vezes o comprimento daquele. Palpo com quatro artículos setosos; primeiro artículo com 1,28-1,50 vezes o seu próprio diâmetro, 0,45-0,57 vezes o comprimento do artículo seguinte e oito cerdas; segundo com 2,66-3,00 vezes o seu diâmetro, 0,72-0,85 vezes o comprimento do terceiro artículo e 8-15 cerdas; terceiro com 4,14-5,00 vezes o seu diâmetro, $0,75-0,85$ vezes o comprimento do artículo seguinte e 20 cerdas; quarto com 4,57-5,00 vezes o seu diâmetro e 32 cerdas. Labela com seis cerdas marginais e nove medianas, hipofaringe setulosa no ápice e com cerdas medianas. Tórax: 
escuto com quatro fileiras irregulares longitudinais de cerdas (duas dorsocentrais e duas dorso laterais). Asa: venação como na figura 4. Tarsos com garras denteadas e aproximadamente tão longas quanto o empódio (Fig. 5). Abdômen: genitália (Fig. 7) - lobos mediodorsais do gonocoxito bem desenvolvidos e pilosos; hipoprocto com dois lobos pilosos, cada qual portando duas cerdas apicais e aproximadamente tão longo quanto os lobos do gonocoxito; cerco bilobado, distintamente mais amplo qua o hipoprocto, com várias cerdas apicais e mais curto qua o hipoprocto; gnóstilo gradualmente afilado em direção à extremidade; edeago alongado, atilando gradativamente para a extremidade e com ápice reto.

Fêmea adulta. Comprimento: 4,6-6,3mm; asa: 3,1-5,6mm. Difere do macho: antena com 29 tlagelômeros, separados por um pescoço curto e ornados como na figura 3. Ovipositor (Fig. 8) pouco protátil, cercos arredondados, não fundidos e setosos, hipoprocto setoso (Fig. 10).

Pupa. Comprimento: 3,9-5,2 mm. Cabeça (Fig. 11): dois pares de papilas verticais (um setoso e um não setoso), cerda apical mais curta que a largura da base antenal; dois pares de papilas faciais inferiores (um setoso e um não setoso); três pares de papilas faciais laterais (um setoso e dois não setosos). Tórax: espiráculo alongado e curvo, com $0,4 \mathrm{~mm}$ de comprimento. Abdômen: segmentos II-VIII com três a quatro fileiras longitudinais irregulares de espinhos de tamanho variado e uma fileira longitudinal irregular de espinhos diminutos. Os três pares de pernas alcançando o segmento IV, o primeiro par terminando após a metade do comprimento do segmento; o segundo terminando aproximadamente nesta e o terceiro anteriormente a esta.

Larva. Coloração: amarela. Comprimento: 1,9-3,4mm. Aspecto geral como na fígura 12, Tórax: dois grupos de três papilas laterais setosas de cada lado da espétula (Fig. 13). Segmentos torácicos com dois pares de papilas dorsais setosas, dois pares de papilas pleurais setosas, um par de papilas esternais setosas e um par de papilas ventrais setosas. Abdômen: segmentos I-VII com espiráculos laterais e com dois pares de papilas dorsais setosas, dois pares de papilas esternais setosas, dois pares de papilas pleurais setosas e um par de papilas ventrais setosas; segmento VIII com espiráculos deslocados para a margem inferior e com um par de papilas dorsais setosas, dois pares de papilas pleurais setosas (Fig. 14) e dois pares de papilas ventrais setosas (Fig. 15); segmento terminal com três pares de papilas terminais setosas e dois pares de papilas anais setosas (Fig. 16). Ânus em fenda longitudinal ventral (Fig. 16).

Holótipo macho. Brasil, Rio de Janeiro: Maricá (Restinga de Barra de Maricá), 06. VII. 1992. Parátipos: mesma procedência, um macho, 19.VII.1987; um macho, 22.VII. 1993; quatro fềmeas, 19.VII.1987; uma fêmea, 06. VII. 1992; uma fềmea, 29. VIII. 1993; duas exúvias, 19.VII. 1987; duas exúvias, 06. VII. 1992; uma exúvia, 22. VIII. 1993; quatro larvas, 06. VII. 1992; duas larvas, 29. VIII. 1993. Obtidos de galhas em Myrciaria floribunda.

Galha. Complexa, desenvolvida a partir de gemas apicais e axilares, amarela ou verde, unilocular e formada por duas valvas (Fig. 17). Esta espécie somente abandona as galhas por ocasião da emergência. 


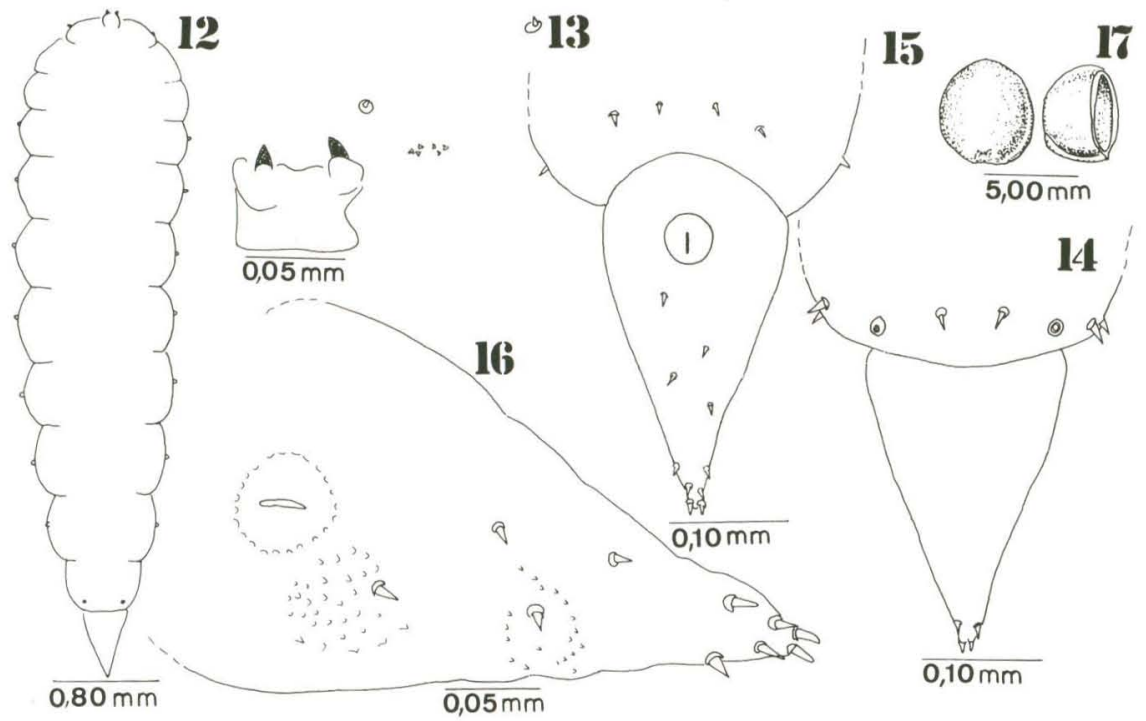

Figs 12-17. Myrciaricanyia bivalva, sp.n. (12) Larva, aspecto geral; (13) larva, espátula protorácica; (14) larva, segmento abdominal VIII, vista dorsal: (15) larva, segmento VIII, vista ventral; (16) larva, segmento terminal; (17) galha, aspecto geral.

AGRADECIMENTOS. Ao Sr. Atidio Manhã do Departamento de Botânica da Universidade Federal do Rio de Janciro, pelo desenho da galha.

\section{REFERÊNCIAS BIBLIOGRÁFICAS}

Gagné, R.J. 1989. The plant-Feeding Gall Midges of North America. Ithaca, Comstock Cornell University Press, 356p.

KiefFer, J.J. \& P. HeRbST. 1911. Üher Gallen und Gallentiere aus Chile. Centr. Bakteriol. \& Parasitol. 29: 696-704.

Silva, J.G. \& G.V. SONNER. 1984. A vegetação de Restinga na Barra de Maricá, RJ. In: L.D.DE Lacerda; R. Cerqueira \& B. TurcQ (ed.) Restingas: origem, estrutura, processos. Niterói, CEUFF. 